\title{
Mars Exploration Rovers Entry, Descent, and Landing Trajectory Analysis
}

\author{
Prasun N. Desai* \\ NASA Langley Research Center, Hampton, VA 23681-2199 \\ Philip C. Knocke ${ }^{\dagger}$ \\ Jet Propulsion Laboratory, California Institute of Technology, Pasadena, CA 91109-8099
}

\begin{abstract}
The Mars Exploration Rover mission successfully landed two rovers "Spirit" and "Opportunity" on Mars on January $4^{\text {th }}$ and $25^{\text {th }}$ of 2004 , respectively. The trajectory analysis performed to define the entry, descent, and landing (EDL) scenario is described. The entry requirements and constraints are presented, as well as uncertainties used in a Monte Carlo dispersion analysis to statistically assess the robustness of the entry design to off-nominal conditions. In the analysis, six-degree-of-freedom and three-degree-of-freedom trajectory results are compared to assess the entry characteristics of the capsule. Comparison of the preentry results to preliminary post-landing reconstruction data shows that all EDL parameters were within the requirements. In addition, the final landing position for both "Spirit" and "Opportunity" were within $15 \mathrm{~km}$ of the predicted landing location.
\end{abstract}

\section{Introduction}

$\mathrm{T}$ he Mars Exploration Rover (MER) mission's "Spirit" and "Opportunity" spacecrafts successfully landed on January $4^{\text {th }}$ and $25^{\text {th }}$ of 2004 , respectively. The Landers were targeted to the equatorial region of Mars with Spirit landed in Gusev crater $\left(14.59^{\circ} \mathrm{S}, 175.3^{\circ} \mathrm{E}\right)$ and Opportunity landed in Meridiani Planum $\left(1.98^{\circ} \mathrm{S}, 5.94^{\circ} \mathrm{W}\right)$. Each Lander carried a rover to explore the surface of Mars making in-situ measurements. However, unlike the Mars Pathfinder Sojourner rover, these rovers are larger and more capable accommodating an increased suite of science instruments, and have been able to traverse greater distances during surface operations. Reference 1 gives an overview of the MER mission.

Both Landers delivered the rovers to the surface utilizing the same entry, descent, and landing (EDL) scenario that was developed and successfully implemented by Mars Pathfinder (MPF). ${ }^{2}$ The capsules decelerated with the aid of an aeroshell, a supersonic parachute, retrorockets, and air bags for safely landing on the surface (see Fig. 1). Reference 3 gives a description of the EDL system.

An overview of the EDL sequence of events is first presented, followed by the entry trajectory requirements and constraints, along with the uncertainties utilized in the Monte Carlo dispersion analysis. A description of the sixdegree-of-freedom (DOF) and three-degree-of-freedom trajectory simulations is then provided and the results compared to assess the entry characteristics. The Monte Carlo dispersion analysis is performed to statistically assess the robustness of the entry design to off-nominal conditions to assure that all EDL requirements are satisfied. For example, evaluating the attitude dynamics of the capsule during the entry near peak heating and at parachute deployment, along with the parachute deployment conditions (dynamic pressure and Mach number). This information is necessary for defining requirements for the thermal protection and parachute subsystems. Finally, results from the postlanding reconstruction are presented and compared with the pre-entry predictions.

\section{EDL Overview}

The MER EDL sequence is illustrated in Fig 1. Upon Mars arrival, the landers are separated from their respective cruise stages 15 minutes prior to atmospheric entry. Parachute deployment is determined by the on-board flight soft-

\footnotetext{
* Senior Aerospace Engineer, Aerospace Systems, Concepts and Analysis Competency, 100 NASA Rd., MS 365, Hampton, VA 23681-2199, AIAA Associate Fellow.

${ }^{\dagger}$ Member of Engineering Staff, Navigation and Mission Design Section, Jet Propulsion Laboratory, 4800 Oak Grove Dr., M/S 264-820, Pasadena, CA 91109-8099. 
ware based on vehicle deceleration measurements obtained from two Litton LN-200 Inertial Measurement Units (IMU); one mounted in the backshell is used in conjunction with another inside the rover. Deployment is nominally targeted at a dynamic pressure of $700 \mathrm{~N} / \mathrm{m}^{2}$ (occurring at approximately $244 \mathrm{~s}$ after entry interface) which corresponds to an altitude of $\sim 9.5 \mathrm{~km}$. The heatshield is jettisoned $20 \mathrm{~s}$ after parachute deployment. The lander descent along its bridle is initiated $10 \mathrm{~s}$ thereafter. At an altitude of $2.4 \mathrm{~km}$ above ground level (AGL), a radar altimeter acquires the ground. The radar altimeter, with its antenna mounted at one of the lower corners of the lander tetrahedron, provides distance measurements to the local surface for use by the on-board flight software to determine the solution time for firing the Rocket Assisted Deceleration (RAD) system (at $\sim 120 \mathrm{~m}$ AGL). Airbag inflation occurs approximately $0.5 \mathrm{~s}$ prior to RAD firing. The objective of the RAD rockets is to zero the vertical velocity of the lander $\sim 12 \mathrm{~m}$ above the ground. The bridle is then cut, and the inflated airbag/lander configuration freefalls to the surface. Sufficient impulse remains in the retrorocket motors to carry the backshell and parachute to a safe distance away from the lander.

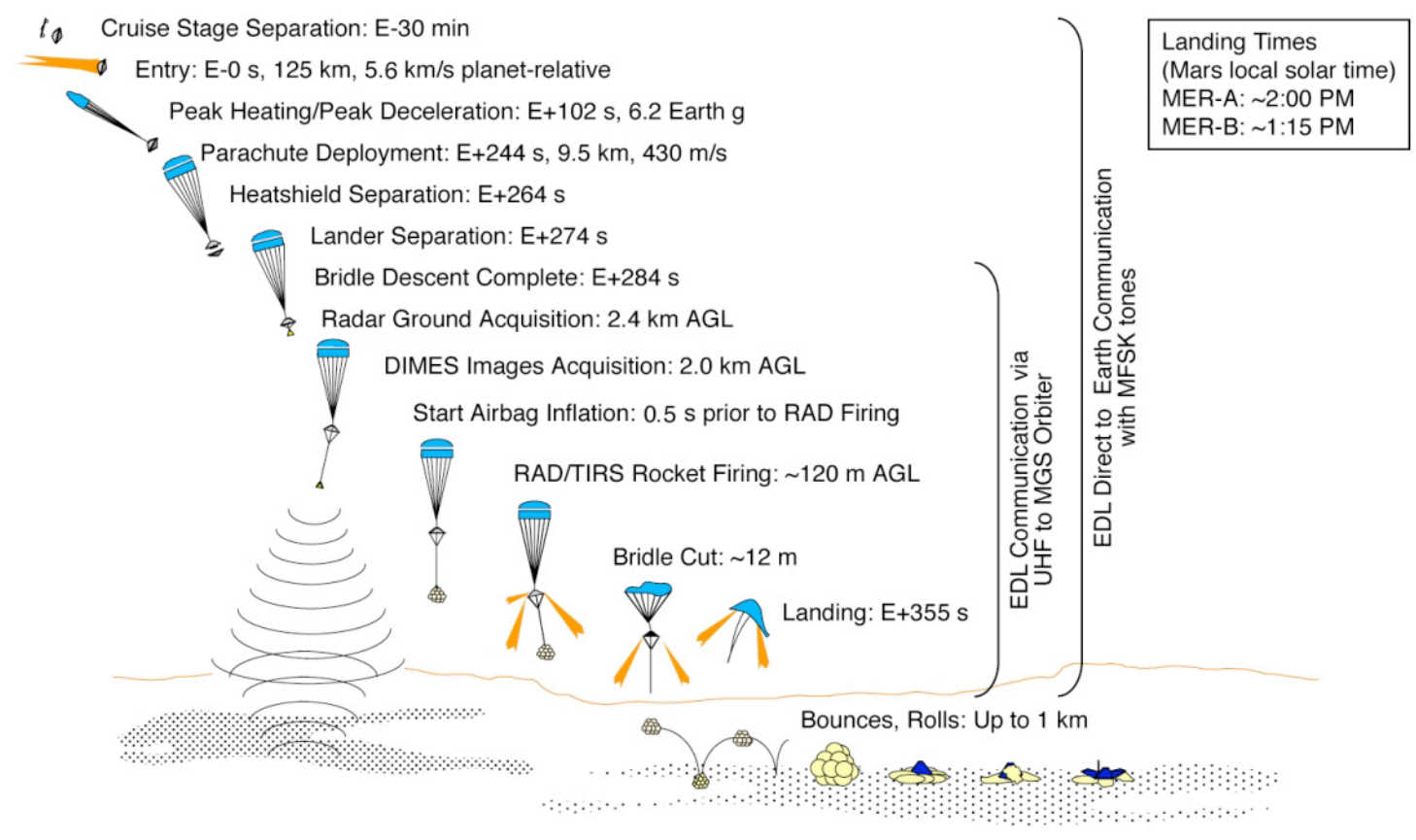

Figure 1. MER Entry, Descent, and Landing Sequence.

The MER landers entered Mars' atmosphere directly from their interplanetary transfer trajectories with inertial entry velocities of $5.63 \mathrm{~km} / \mathrm{s}$ for "Spirit" and $5.70 \mathrm{~km} / \mathrm{s}$ for "Opportunity". The nominal inertial entry flight-path angle selected for MER is $-11.5 \mathrm{deg}$. For comparison, the MPF inertial entry flight-path angle was steeper having a value of -14.2 deg. The MER entry angle was chosen to be as shallow as possible to accommodate the entry mass, while still satisfying the requirement of maintaining a $1.0 \mathrm{deg}$ margin between the 3- $\sigma$ shallow and the skip-out entries. (Skip-out was defined as the steepest flight-path angle at which the time derivative of the trajectory radius first goes to zero. This situation occurs at a slightly steeper entry angle than a true flyby trajectory.) For MER, the skip-out boundary occurred at an inertial flight-path angle of $-9.6 \mathrm{deg}$.

Hypersonic deceleration is accomplished utilizing an aeroshell. The MER aeroshell is based on the MPF design with only minor changes to increase inside volume (Fig. 2).

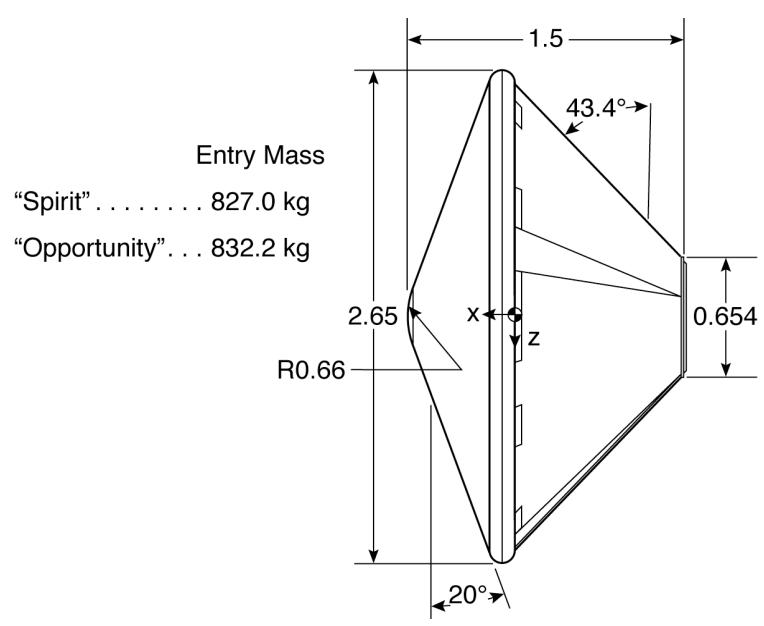

Figure 2. MER Entry Aeroshell Configuration (all dimensions in meters). 
The aeroshell consists of a forebody heatshield and an aftbody backshell. The forebody shape is a Viking heritage 70 deg half-angle sphere cone. Prior to entry, the capsule (spinning at $2 \mathrm{rpm}$ ) is separated from the cruise stage. The capsule has no active control system, so the spin rate maintains its inertial attitude (targeted nominally for zero angle-of-attack at atmospheric interface) during coast. Throughout the atmospheric entry, the passive capsule relies solely on aerodynamic stability for performing a controlled descent through all aerodynamic flight regimes: free molecular, transitional, hypersonic-continuum, and supersonic. The capsule must possess sufficient aerodynamic stability to minimize any angle-of-attack excursions during the severe heating environment. Additionally, this stability must persist through the supersonic regime to maintain a controlled attitude at parachute deployment. Reference 4 provides a description of the MER capsule aerodynamics.

\section{Trajectory Simulation}

\section{A. Entry Trajectory Requirements and Constraints}

The MER atmospheric entry trajectory is designed to fit within an envelope of derived requirements and physical constraints based upon the lander hardware design. As such, for a successful landing, all entry requirements must be satisfied. Table 1 lists all the EDL requirements and their specific bound. A Monte Carlo dispersion analysis is performed to assess the satisfaction of these requirements.

\section{B. Atmosphere Model}

The atmosphere model utilized by MER in the entry trajectory design and analysis was the Kass-Schofield model. ${ }^{5}$ This model was developed specifically for the two landing sites in an effort to predict the most accurate atmospheric properties that would be encountered during the actual landing times. This model takes into account variations in diurnal, seasonal, positional, and site topography to produce mean density, temperature, and pressure profiles, and their statistical perturbations. Figure 3 shows examples of 5 perturbed density profiles (as a percentage of the mean) produced by the Kass-Schofield model. Also, depicted are the $\pm 3-\sigma$ bounds of the density variation. Similarly, another model was created using Mesoscale simulation techniques to predict winds that would be encountered at the two sites. ${ }^{6}$

\section{Entry Covariance}

Initial conditions at entry are obtained from orbit determination performed by the MER Navigation Team. Reference 7 gives an in depth description of the Navigation process during the cruise phase to Mars and the determination of the final arrival conditions prior to entry. The navigation accuracy obtained by MER yielded extremely small state errors upon Mars arrival for both landings. The 3- $\sigma$ inertial flight-path angle error obtained for "Spirit" and "Opportunity" were $\pm 0.01^{\circ}$ and $\pm 0.02^{\circ}$, respectively.
Table 1: EDL Requirements and Constriants

\begin{tabular}{lc}
\hline \multicolumn{1}{c}{ Requirement } & Limit \\
\hline$\alpha_{\mathrm{T}}$ at atmospheric entry, deg & $<10$ \\
Max heat rate, $\mathrm{W} / \mathrm{cm}^{2}$ & $<56.5$ \\
Max heat load, $\mathrm{J} / \mathrm{cm}^{2}$ & $<3815$ \\
$\alpha_{\mathrm{T}}$ at max heat rate, deg & $<8$ \\
Max stagnation pressure, $\mathrm{kPa}$ & $<25$ \\
Max deceleration, Earth $\mathrm{g}$ & $<8$ \\
$\alpha_{\mathrm{T}}$ at parachute deploy, deg & $<13$ \\
Dynamic Pressure at parachute deployment, $\mathrm{N} / \mathrm{m}^{2}$ & $<900$ \\
Mach number at parachute deployment & $<2.1$ \\
Mach number at heatshield separation & $<0.6$ \\
Deceleration at lander separation, Earth $\mathrm{g}$ & $<0.53$ \\
Time from parachute deployment to RAD firing, $\mathrm{s}$ & $>57$ \\
Velocity at RAD firing, m/s & $<93$ \\
\hline
\end{tabular}

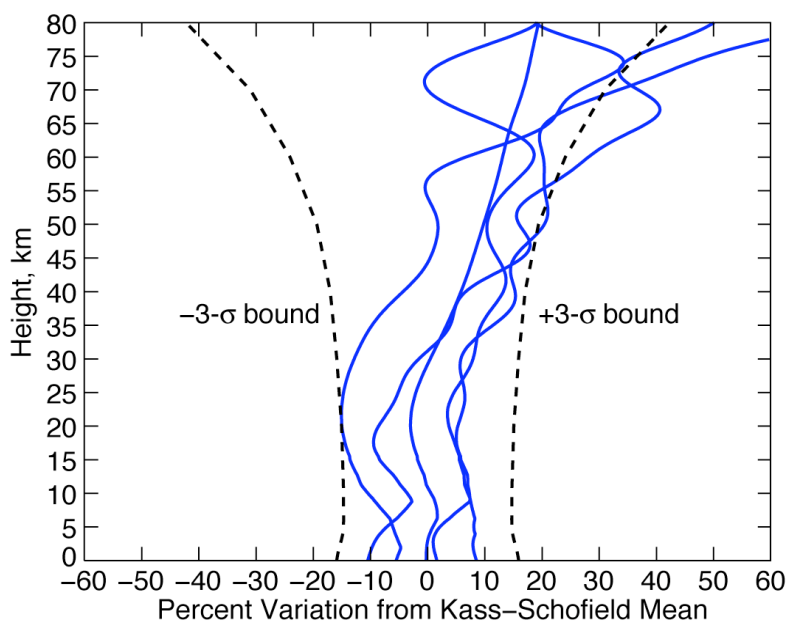

Figure 3. Density Variation from Kass-Schofield Model.

\section{Cruise-Stage Separation}

Based on the final cruise-stage and capsule mass properties, a statistical multi-body separation analysis was performed to predict separation attitude and attitude rates errors. The attitude errors predicted in pitch and yaw are $\pm 1.7 \mathrm{deg}$ and $\pm 2.7 \mathrm{deg}$, respectively. The attitude rate errors predicted in pitch and yaw are $\pm 0.4 \mathrm{deg} / \mathrm{s}$ and \pm 0.4 
$\mathrm{deg} / \mathrm{s}$, respectively, and a roll rate error of $\pm 1.2 \mathrm{deg} / \mathrm{s}$. These variations are used as inputs in the Monte Carlo analysis.

\section{E. Trajectory Analysis}

Two trajectory propagation codes were utilized for MER landing dispersion analyses: the Program to Optimize Simulated Trajectories (POST) program ${ }^{8}$ developed at the NASA Langley Research Center (LaRC), and the Atmospheric-Entry Powered Landing (AEPL) program ${ }^{9}$ developed at the Jet Propulsion Laboratory (JPL). Both programs used the same LaRC-developed aerodynamics database (see Ref. 4), which provided drag and other aerodynamic coefficients as a function of Mach number and capsule angle-of-attack. Also common between the two programs were the atmospheric density models, ${ }^{5}$ mesoscale wind models, ${ }^{6}$ and the spacecraft parameters. Both programs modeled descent configuration changes (heatshield separation, airbag inflation, etc.) and non-instantaneous parachute deployment and retro-rocket firing.

The POST trajectory analysis was performed modeling "six-degree-of-freedom" (6DOF) dynamics, in which all forces and torques on the spacecraft are included, from atmospheric interface to parachute deployment. During this portion of the entry, the full set of capsule aerodynamics and mass properties were incorporated into the simulation to accurately model the hypersonic descent. From parachute deployment to landing, "three-degree-of-freedom" (3DOF) dynamics were used, in which only the drag force is modeled and is assumed to act opposite the windrelative velocity vector. The POST trajectory simulation seamlessly transitions from 6DOF to 3DOF dynamics within a single continuous simulation.

The version of the AEPL program used for MER employed 3DOF analyses throughout. Since the MER entries were unguided and ballistic, the 3DOF results from AEPL agreed well with the POST 6DOF/3DOF simulation. AEPL was also used in maneuver design, in conjunction with the navigation cruise trajectory propagation and targeting programs.

\section{F. Monte Carlo Dispersion Analysis}

A Monte Carlo dispersion analysis is utilized to statistically assess the robustness of the entry design to offnominal conditions to assure that all EDL requirements and constraints are satisfied (see Table 1). The two simulations were employed for the MER project for independent verification of the results. Table 2 lists all the input variables that are randomly varied in the Monte Carlo dispersion analysis, along with their respective variance and distribution type. The analysis includes uncertainties in the initial state vector, capsule mass properties (mass, centerof-gravity, inertia), initial attitude and attitude rates, hypersonic aerodynamic coefficients, atmospheric density and winds, parachute drag, and drag of various terminal descent configurations.

Table 2: Monte Carlo Analysis Variables

\begin{tabular}{lcc}
\hline \hline \multicolumn{1}{c}{ Variable } & 3- $\sigma$ Variation & Distribution \\
\hline Entry states & Based on covariance & - \\
Mass, kg & See Ref. 7) & Gaussian \\
Radial center-of-gravity offset, $\mathrm{mm}$ & \pm 2.3 & Gaussian \\
Axial center-of-gravity, mm & \pm 0.325 & Gaussian \\
Moments of Inertia (Ixx, Iyy, Izz) & \pm 15.0 & Gaussian \\
Cross products (Ixy, Ixz, Iyz), kg-m & $1 \%, 5 \%, 5 \%$ & Gaussian \\
Entry pitch and yaw attitude, deg & $\pm 0.001, \pm 0.002, \pm 1.1$ & Gaussian \\
Entry pitch and yaw rates, deg/s & $\pm 1.7, \pm 2.7$ & Gaussian \\
Entry roll rate, deg/s & $\pm 0.4, \pm 0.4$ & Gaussian \\
Hypersonic aerodynamic coefficients & \pm 1.2 & Gaussian \\
Parachute $C_{D}$ & See Ref. 4 & Uniform \\
Backshell+Lander $C_{D}$ & $\pm 12 \%(3-\sigma)$ & Gaussian \\
Lander $C_{D}$ (airbag stowed) & $\pm 5 \%(3-\sigma)$ & Gaussian \\
Backshell $C_{D}$ & $\pm 20 \%(3-\sigma)$ & Gaussian \\
Lander $C_{D}$ (airbag inflated) & $\pm 5 \%(3-\sigma)$ & Gaussian \\
Atmosphere & $\pm 20 \%(3-\sigma)$ & \\
& Kass-Schofield model & \\
\hline \hline
\end{tabular}


Table 3: "Spirit" Monte Carlo Results

\begin{tabular}{|c|c|c|c|c|c|c|}
\hline \multirow[b]{2}{*}{ Parameter } & \multirow[b]{2}{*}{ Units } & \multicolumn{2}{|c|}{ 6DOF } & \multicolumn{2}{|c|}{ 3DOF } & \multirow[t]{2}{*}{ Reconstructed } \\
\hline & & Mean & 3-o Range & Mean & 3-o Range & \\
\hline \multicolumn{7}{|l|}{ Hypersonic Flight } \\
\hline Peak Heating Rate & $\mathrm{W} / \mathrm{cm}^{2}$ & 39.9 & $38.1-41.7$ & $45.0^{\mathrm{b}}$ & $42.9^{\mathrm{b}}-47.1^{\mathrm{b}}$ & \\
\hline Attitude@Peak Heat Rate & deg & 0.6 & $0-2.2$ & $-^{\mathrm{a}}$ & $-^{\mathrm{a}}$ & 1.8 \\
\hline Peak Acceleration & Earth $g$ & 5.9 & $5.5-6.3$ & 5.9 & $5.5-6.3$ & 5.6 \\
\hline Peak Stag Pressure & $\mathrm{N} / \mathrm{m}^{2}$ & 9984 & $9263-10705$ & 9955 & $9253-10657$ & \\
\hline Total Heat Load & $\mathrm{J} / \mathrm{cm}^{2}$ & 2770 & $2669-2870$ & $3247^{\mathrm{b}}$ & $3136^{\mathrm{b}}-3358^{\mathrm{b}}$ & \\
\hline \multicolumn{7}{|l|}{ Parachute Deployment } \\
\hline Time from Entry & $\mathrm{sec}$ & 245.6 & $237.3-253.8$ & 245.5 & $237.9-253.1$ & 251 \\
\hline Height & $\mathrm{km}$ & 8.6 & $6.1-11.1$ & 8.7 & 6.3-11.1 & 7.54 \\
\hline Wind-Relative Velocity & $\mathrm{m} / \mathrm{s}$ & 417.7 & $389.9-445.6$ & $407.0^{\mathrm{c}}$ & $377.5^{\mathrm{c}}-436.5^{\mathrm{c}}$ & 411 \\
\hline Mach Number & & 1.78 & $1.71-1.85$ & 1.78 & $1.71-1.85$ & \\
\hline Dynamic Pressure & $\mathrm{N} / \mathrm{m}^{2}$ & 724.2 & $654.5-794.0$ & 725.6 & $654.8-796.3$ & 730 \\
\hline Planet-Relative FPA & $\operatorname{deg}$ & -28.2 & $-30.0--26.4$ & -28.1 & $-29.9--26.3$ & \\
\hline Attitude & deg & 1.1 & $0-4.9$ & $-^{\mathrm{a}}$ & $-^{\mathrm{a}}$ & 7 \\
\hline \multicolumn{7}{|l|}{ Heatshield Jettison } \\
\hline Time from Entry & $\mathrm{sec}$ & 265.6 & $257.3-273.8$ & 265.5 & $257.9-273.1$ & 271 \\
\hline Height & $\mathrm{km}$ & 6.4 & 3.9-8.9 & 6.4 & $4.0-8.8$ & \\
\hline Wind-Relative Velocity & $\mathrm{m} / \mathrm{s}$ & 112.2 & $94.1-130.3$ & $108.9^{\mathrm{c}}$ & $88.7^{\mathrm{c}}-129.1^{\mathrm{c}}$ & \\
\hline Planet-Relative FPA & $\operatorname{deg}$ & -49.6 & $-55.6--43.6$ & -49.6 & $-55.7--43.5$ & \\
\hline Dynamic Pressure & $\mathrm{N} / \mathrm{m}^{2}$ & 60.8 & $45.2-76.4$ & $-^{\mathrm{a}}$ & $-^{\mathrm{a}}$ & \\
\hline Mach number & & 0.47 & $0.4-0.54$ & 0.47 & $0.4-0.53$ & \\
\hline \multicolumn{7}{|l|}{ Lander Descent Initiation } \\
\hline Time from Entry & sec & 275.6 & $267.3-283.8$ & 275.5 & $267.9-283.1$ & 281 \\
\hline Height & $\mathrm{km}$ & 5.6 & $3.1-8.1$ & 5.6 & $3.2-8.1$ & \\
\hline Wind-Relative Velocity & $\mathrm{m} / \mathrm{s}$ & 90.6 & $77.4-103.9$ & $90.5^{\mathrm{c}}$ & $75.1^{\mathrm{c}}-105.8^{\mathrm{c}}$ & \\
\hline Planet-Relative FPA & deg & -62.0 & $-70.4--53.6$ & -62.1 & $-70.7--53.5$ & \\
\hline Dynamic Pressure & $\mathrm{N} / \mathrm{m}^{2}$ & 41.8 & $31.8-51.8$ & $-^{\mathrm{a}}$ & $-^{\mathrm{a}}$ & \\
\hline Sensed Acceleration & Earth $g$ & 0.43 & $0.39-0.46$ & 0.43 & $0.39-0.46$ & \\
\hline \multicolumn{7}{|l|}{ RAD Initiation } \\
\hline Time from Entry & $\mathrm{sec}$ & 345.8 & $316.2-375.3$ & 346.7 & $317.3-376.2$ & 339.4 \\
\hline Time from Chute Deploy & $\mathrm{sec}$ & 100.2 & $64.4-136.0$ & 101.3 & $65.3-137.2$ & 88.4 \\
\hline Height & $\mathrm{m}$ & 123.1 & $91.3-154.7$ & 118.4 & $87.1-149.6$ & 99.4 \\
\hline Wind-Relative Velocity & $\mathrm{m} / \mathrm{s}$ & 73.1 & $61.6-84.5$ & $73.0^{\mathrm{c}}$ & $61.8^{\mathrm{c}}-84.2^{\mathrm{c}}$ & 69.2 \\
\hline Planet-Relative FPA & $\operatorname{deg}$ & -83.9 & $-89.9--76.3$ & -84.1 & $-89.6--77.4$ & \\
\hline Mach number & 0.29 & $0.24-0.34$ & 0.29 & $0.24-0.33$ & & \\
\hline \multicolumn{7}{|l|}{ Bridle Cut } \\
\hline Time from Entry & $\mathrm{sec}$ & $348.2^{\mathrm{d}}$ & $319.7^{\mathrm{d}}-376.3^{\mathrm{d}}$ & 349.7 & $320.6-378.7$ & \\
\hline Height & $\mathrm{m}$ & $12.4^{\mathrm{d}}$ & $4.2^{\mathrm{d}}-20.1^{\mathrm{d}}$ & 13.6 & $11.1-16.1$ & 8.5 \\
\hline Wind-Relative Velocity & $\mathrm{m} / \mathrm{s}$ & $9.8^{\mathrm{d}}$ & $0.2^{\mathrm{d}}-25.3^{\mathrm{d}}$ & $9.3^{\mathrm{c}}$ & $0.3^{\mathrm{c}}-20.4^{\mathrm{c}}$ & 11.8 \\
\hline \multicolumn{7}{|l|}{ Landing } \\
\hline Time from Entry & $\mathrm{sec}$ & $350.5^{\mathrm{d}}$ & $321.0^{\mathrm{d}}-379.5^{\mathrm{d}}$ & 352.3 & $322.9-381.5$ & \\
\hline Wind-Relative Velocity & $\mathrm{m} / \mathrm{s}$ & $13.9^{\mathrm{d}}$ & $7.2^{\mathrm{d}}-25.0^{\mathrm{d}}$ & $13.9^{\mathrm{c}}$ & $6.7^{\mathrm{c}}-21.2^{\mathrm{c}}$ & 14.0 \\
\hline
\end{tabular}

${ }^{\mathrm{a}}$ Computed in $6 \mathrm{DOF}$ only, ${ }^{\mathrm{b}}$ Different calculation method used, ${ }^{\mathrm{c}}$ Planet-relative velocity listed,

${ }^{\mathrm{d}}$ Results obtained from 24DOF multi-body POST simulation. 
Table 4: "Opportunity" Monte Carlo Results

\begin{tabular}{|c|c|c|c|c|c|c|}
\hline \multirow[b]{2}{*}{ Parameter } & \multirow[b]{2}{*}{ Units } & \multicolumn{2}{|c|}{ 6DOF } & \multicolumn{2}{|c|}{ 3DOF } & \multirow[t]{2}{*}{ Reconstructed } \\
\hline & & Mean & 3- $\sigma$ Range & Mean & 3- $\sigma$ Range & \\
\hline \multicolumn{7}{|l|}{ Hypersonic Flight } \\
\hline Peak Heating Rate & $\mathrm{W} / \mathrm{cm}^{2}$ & 42.2 & $39.3-45.2$ & $47.9^{\mathrm{b}}$ & $44.6^{\mathrm{b}}-51.1^{\mathrm{b}}$ & \\
\hline Attitude@Peak Heat Rate & deg & 0.6 & $0-2.1$ & $-^{\mathrm{a}}$ & $-^{\mathrm{a}}$ & 2.1 \\
\hline Peak Acceleration & Earth $g$ & 6.4 & $5.9-7.0$ & 6.4 & $5.9-7.0$ & 6.3 \\
\hline Peak Stag Pressure & $\mathrm{N} / \mathrm{m}^{2}$ & 10835 & $9868-11803$ & 10812 & $9863-11760$ & \\
\hline Total Heat Load & $\mathrm{J} / \mathrm{cm}^{2}$ & 2711 & $2595-2826$ & $3190^{\mathrm{b}}$ & $3064^{b}-3317^{b}$ & \\
\hline \multicolumn{7}{|l|}{ Parachute Deployment } \\
\hline Time from Entry & $\mathrm{sec}$ & 242.1 & $234.5-249.7$ & 242.1 & $235.2-249.0$ & 250.3 \\
\hline Height & $\mathrm{km}$ & 8.7 & $6.4-11.0$ & 8.8 & $6.6-11.0$ & 7.52 \\
\hline Wind-Relative Velocity & $\mathrm{m} / \mathrm{s}$ & 438.0 & $411.8-464.2$ & $425.3^{\mathrm{c}}$ & $395.4^{\mathrm{c}}-455.2^{\mathrm{c}}$ & 434 \\
\hline Mach Number & & 1.86 & $1.78-1.94$ & 1.86 & $1.79-1.94$ & \\
\hline Dynamic Pressure & $\mathrm{N} / \mathrm{m}^{2}$ & 747.0 & $674.7-819.3$ & 749.1 & $676.3-821.9$ & 764 \\
\hline Planet-Relative FPA & $\operatorname{deg}$ & -26.8 & $-28.4--25.1$ & -26.7 & $-28.3--25.2$ & \\
\hline Attitude & $\operatorname{deg}$ & 1.0 & $0-4.4$ & $-^{\mathrm{a}}$ & $-^{\mathrm{a}}$ & 8 \\
\hline \multicolumn{7}{|l|}{ Heatshield Jettison } \\
\hline Time from Entry & $\mathrm{sec}$ & 262.2 & $254.6-269.8$ & 262.1 & $255.2-269.0$ & 270.3 \\
\hline Height & $\mathrm{km}$ & 6.5 & 4.2-8.8 & 6.5 & 4.3-8.8 & \\
\hline Wind-Relative Velocity & $\mathrm{m} / \mathrm{s}$ & 116.9 & $99.3-134.5$ & $113.1^{\mathrm{c}}$ & $94.1^{\mathrm{c}}-132.1^{\mathrm{c}}$ & \\
\hline Planet-Relative FPA & $\operatorname{deg}$ & -47.6 & $-53.0--42.2$ & -47.6 & $-53.3--42.0$ & \\
\hline Dynamic Pressure & $\mathrm{N} / \mathrm{m}^{2}$ & 63.5 & $47.1-80.0$ & $-{ }^{\mathrm{a}}$ & $-^{\mathrm{a}}$ & \\
\hline Mach number & 0.49 & $0.42-0.56$ & 0.49 & $0.42-0.56$ & & \\
\hline \multicolumn{7}{|l|}{ Lander Descent Initiation } \\
\hline Time from Entry & $\mathrm{sec}$ & 272.1 & $264.6-279.8$ & 272.1 & $265.2-281.8$ & 280.3 \\
\hline Height & $\mathrm{km}$ & 5.7 & $3.3-8.0$ & 5.7 & $3.5-8.2$ & \\
\hline Wind-Relative Velocity & $\mathrm{m} / \mathrm{s}$ & 91.0 & $81.0-106.9$ & $92.1^{\mathrm{c}}$ & $78.6^{\mathrm{c}}-113.9^{\mathrm{c}}$ & \\
\hline Planet-Relative FPA & $\operatorname{deg}$ & -60.6 & $-67.5--53.8$ & -60.7 & $-67.8--53.6$ & \\
\hline Dynamic Pressure & $\mathrm{N} / \mathrm{m}^{2}$ & 43.6 & $33.0-54.3$ & $-{ }^{\mathrm{a}}$ & $-^{\mathrm{a}}$ & \\
\hline Sensed Acceleration & Earth $g$ & 0.44 & $0.40-0.49$ & 0.44 & $0.40-0.48$ & \\
\hline \multicolumn{7}{|l|}{ RAD Initiation } \\
\hline Time from Entry & $\mathrm{sec}$ & 343.7 & $315.9-371.5$ & 344.7 & $317.1-372.2$ & 336.3 \\
\hline Time from Chute Deploy & $\mathrm{sec}$ & 101.5 & $68.2-134.8$ & 102.5 & $69.1-136.0$ & 86 \\
\hline Height & $\mathrm{m}$ & 123.1 & $91.3-154.7$ & 118.5 & $85.4-151.7$ & 127.1 \\
\hline Wind-Relative Velocity & $\mathrm{m} / \mathrm{s}$ & 72.7 & $61.4-84.1$ & $72.7^{\mathrm{c}}$ & $61.1^{\mathrm{c}}-84.4^{\mathrm{c}}$ & 71.1 \\
\hline Planet-Relative FPA & deg & -86.8 & $-89.9--80.9$ & -86.8 & $-89.9--80.7$ & \\
\hline Mach number & & 0.29 & $0.25-0.33$ & 0.29 & $0.24-0.33$ & \\
\hline \multicolumn{7}{|l|}{ Bridle Cut } \\
\hline Time from Entry & $\mathrm{sec}$ & $347.9^{\mathrm{d}}$ & $318.6^{\mathrm{d}}-377.2^{\mathrm{d}}$ & 347.6 & $320.4-374.8$ & \\
\hline Height & $\mathrm{m}$ & $13.1^{\mathrm{d}}$ & $4.5^{\mathrm{d}}-21.7^{\mathrm{d}}$ & 13.4 & $11.4-15.4$ & 6.9 \\
\hline Wind-Relative Velocity & $\mathrm{m} / \mathrm{s}$ & $9.6^{\mathrm{d}}$ & $0.7^{\mathrm{d}}-23.6^{\mathrm{d}}$ & $7.1^{\mathrm{c}}$ & $0.6^{\mathrm{c}}-18.5^{\mathrm{c}}$ & 9.3 \\
\hline \multicolumn{7}{|l|}{ Landing } \\
\hline Time from Entry & $\mathrm{sec}$ & $348.6^{\mathrm{d}}$ & $320.3^{d}-376.9^{d}$ & 350.1 & $322.8-383.3$ & \\
\hline Wind-Relative Velocity & $\mathrm{m} / \mathrm{s}$ & $13.8^{\mathrm{d}}$ & $6.9^{\mathrm{d}}-23.5^{\mathrm{d}}$ & $12.6^{\mathrm{c}}$ & $5.7^{\mathrm{c}}-19.5^{\mathrm{c}}$ & \\
\hline
\end{tabular}

${ }^{\mathrm{a}}$ Computed in 6DOF only, ${ }^{\mathrm{b}}$ Different calculation method used, ${ }^{\mathrm{c}}$ Planet-relative velocity listed,

${ }^{\mathrm{d}}$ Results obtained from 24DOF multi-body POST simulation.

6

American Institute of Aeronautics and Astronautics 
For both the simulations, 2000 random cases were run using the final navigation orbit determination solution for the entry state vector, along with its uncertainty (see Ref. 7). The 3- $\sigma$ inertial flight-path angle error obtained for "Spirit" and "Opportunity" entries were $\pm 0.01^{\circ}$ and $\pm 0.02^{\circ},{ }^{7}$ respectively. Results from the 6DOF/3DOF and 3DOF simulations for the final pre-entry predictions are shown in Table 3 for "Spirit" and Table 4 for "Opportunity". The entry trajectory and attitude conditions are given at critical points during the descent, in terms of the statistical mean and 3- $\sigma$ range. These results are the best apriori estimates of the expected entry conditions and their corresponding range. In general, there is excellent agreement between the two simulations. However, the 6DOF/3DOF results often have a larger variation than the $3 \mathrm{DOF}$ results. This outcome is due to the capsule rotational dynamics that are modeled in the $6 \mathrm{DOF}$ portion of the $6 \mathrm{DOF} / 3 \mathrm{DOF}$ simulation in the hypersonic flight regime which alter the capsule drag coefficient due to changes in the total angle-of-attack $\left(\alpha_{\mathrm{T}}\right)$ arising from uncertainties in the initial attitude/rate, mass properties, and the complete set of aerodynamics.

The pre-entry results indicate that all the entry requirements and constraints are satisfied and well within the limits. Note, due to an observed dust storm on Mars just weeks prior to arrival, the targeted parachute deployment dynamic pressure was increased from the $700 \mathrm{~N} / \mathrm{m}^{2}$ to $725 \mathrm{~N} / \mathrm{m}^{2}$ for the "Spirit" entry and to $750 \mathrm{~N} / \mathrm{m}^{2}$ for the "Opportunity" entry to raise the deployment altitude. This modification was made to hedge against the possibility of encountering a lower density profile than predicted which would reduce the parachute deployment altitude, and thus, the descent timeline from parachute deployment to RAD firing. Figures 4 and 5 show the scatter in the parachute deployment conditions for the two entries demonstrating that they are well within the requirements. The overall size of the landing footprints predicted prior to entry for "Spirit" and "Opportunity" were $73 \times 8 \mathrm{~km}$ and $71 \times 10 \mathrm{~km}$, respectively. Reference 10 gives an in depth description of the landing footprint assessments during the final approach to Mars.

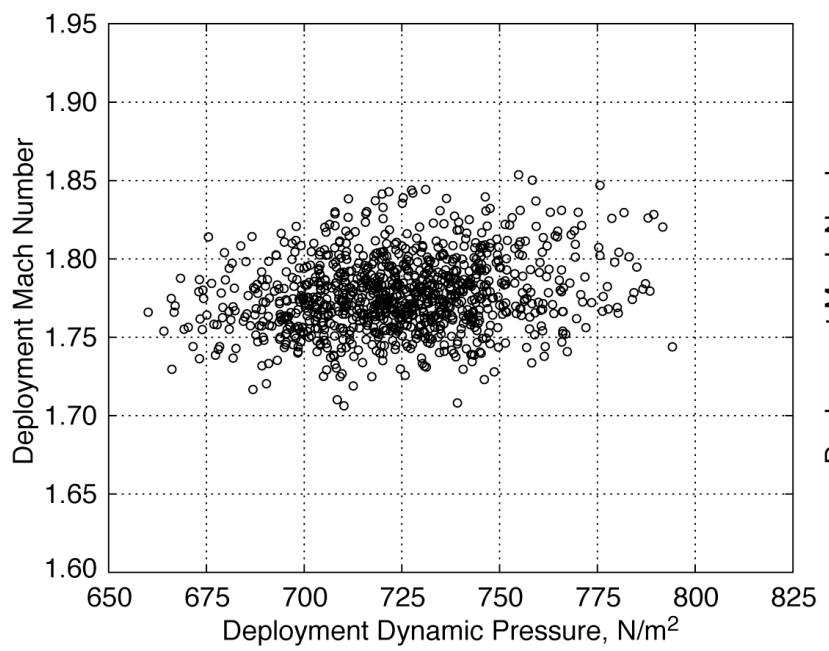

Figure 4. Parachute Deployment Conditions for "Spirit".

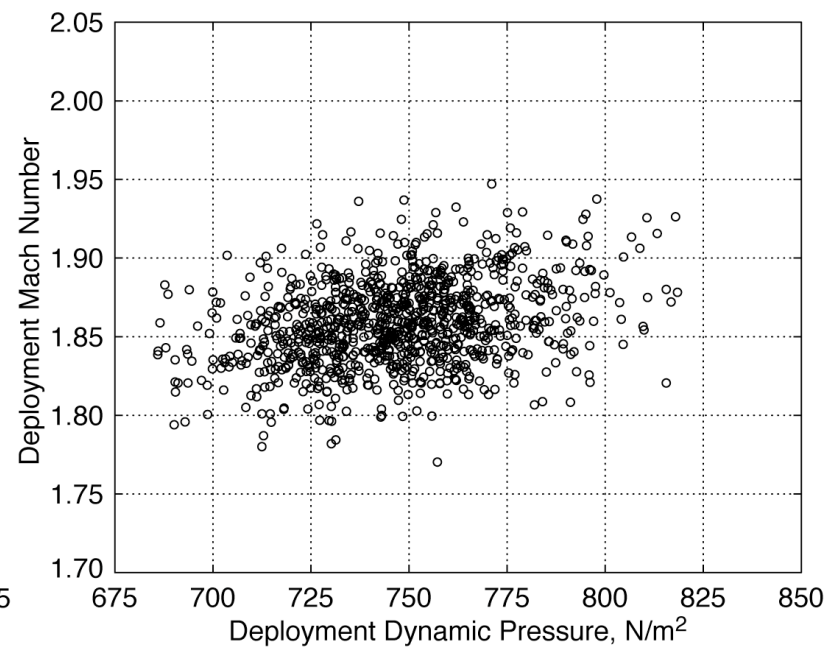

Figure 5. Parachute Deployment Conditions for "Opportunity".

Also listed in Tables 3 and 4 are the trajectory conditions reconstructed thus far from the actual "Spirit" and "Opportunity" flight data obtained during their respective landings. The reconstruction effort is still ongoing, however, preliminary reconstruction results are shown for comparison to the pre-entry predictions. Accelerometer and gyro flight data were recorded during both descents and the parameters that can be reconstructed from this data set are listed. As seen, almost all the reconstructed parameters are well within the pre-entry predicted 3- $\sigma$ variations. However, there are a few parameters that are near or slightly exceed the 3- $\sigma$ variation bounds (e. g., time of and $\alpha_{T}$ at parachute deployment).

For both the "Spirit" and "Opportunity" entries, the time of parachute deployment was later than predicted because a lower density atmosphere was experienced. Based on preliminary atmosphere reconstruction estimates, approximately an $8 \%$ lower density profile (correlating to roughly a 1- $\sigma$ low profile) was encountered in the maximum deceleration region during the "Spirit" descent, while approximately a $12 \%$ lower density profile was encountered during the "Opportunity" descent. This greater reduction in the density profile for "Opportunity" (as compared to "Spirit") is consistent with the observed later time of parachute deployment. 
The landing locations for both "Spirit" and "Opportunity" were within the pre-entry predicted footprint ellipses. "Spirit" landed $13.4 \mathrm{~km}$ downrange from its predicted landing location, while "Opportunity landed $14.9 \mathrm{~km}$ downrange from its predicted landing location. ${ }^{10}$ The reconstruction work is ongoing in order to gain a better understanding of what transpired during the "Spirit" and "Opportunity" landings.

\section{Conclusion}

The Mars Exploration Rover (MER) mission successfully landed two rovers on Mars. The entry trajectory design utilized and the definition of the appropriate trajectory dispersions were critical in the development of the entry, descent, and landing (EDL) system. Monte Carlo dispersion analyses were employed to statistically assess the robustness of the MER entry design to off-nominal conditions. Pre-entry analyses showed that the MER entry design satisfied all EDL requirements. Comparison of preliminary post-landing reconstruction results indicates that both entries were within the EDL requirements defined and the variations defined by the pre-entry Monte Carlo dispersion analyses.

\section{Acknowledgments}

A portion of this research was carried out at the Jet Propulsion Laboratory, California Institute of Technology, under a contract with the National Aeronautics and Space Administration. The authors gratefully acknowledge the contributions of the entire MER EDL Systems Team and the MER Navigation Team.

\section{References}

${ }^{1}$ Roncoli, R. B., and Ludwinski, J. M., "Mission Design Overview for the Mars Exploration Rover Mission," AIAA/AAS Astrodynamics Specialist Conference and Exhibit, AIAA-2002-4823, AIAA, Washington, DC, 2002.

${ }^{2}$ Spencer, D. A., Blanchard, R. C., Braun, R. D., Kallemeyn, P. H., and Thurman, S. W., "Mars Pathfinder Entry, Descent, and Landing Reconstruction," Journal of Spacecraft and Rockets, Vol. 36, No. 3, 1999, pp. 357-366.

${ }^{3}$ Steltzner, A., Desai, P. N., Lee, W. J., and Bruno, R., "The Mars Exploration Rovers Entry Descent and Landing and the Use of Aerodynamic Decelerators," AIAA Aerodynamic Decelerator Systems Technology Conference and Seminar, AIAA- 20032125, AIAA, Washington, DC, 2003.

${ }^{4}$ Desai, P. N., Schoenenberger, M., and Cheatwood, F. M., "Mars Exploration Rovers Six-Degree-of-Freedom Entry Trajectory Analysis," AIAA Paper 03-642, August 2003.

${ }^{5}$ Golombek, M. P., Grant, J. A., Parker, T. J., Kass, D. M., Crisp, J. A., Squyres, S. W., Haldemann, A. F. C., Adler, M., Lee, W., Bridges, N. T., Arvidson, R. E., Carr, M. H., Kirk, R. L., Knocke, P. C., Roncoli, R. B., Weitz, C. M., Schofield, J. T., Zurek, R. W., Christensen, P. R., Fergason, R. L., Andesron, F. S., and Rice Jr., J. W., "Selection of the Mars Exploration Rover Landing Sites," Journal of Geophysical Research, Planets, Vol. 108, No. E12, 10 Dec. 2003, pp. ROV 13-1 to ROV 13-48.

${ }^{6}$ Kass, D. M., Schofield, J. T., Michaels, T. I., Rafkin, S. C. R., Richardson, M. I., and Toigo, A. D., "Analysis of Atmospheric Mesoscale Models for Entry, Descent, and Landing," Journal of Geophysical Research, Vol. 108, No. E12, 25 Nov. 2003, pp. ROV 31-1 to ROV 31-12.

${ }^{7}$ D'Amario, L. A., "Mars Exploration Rovers Navigation Results," AIAA/AAS Astrodynamics Specialist Conference, AIAA-2004-4980, AIAA, Washington, DC, 2004 (to be published).

${ }^{8}$ Brauer, G. L., Cornick, D. E., and Stevenson, R., "Capabilities and Applications of the Program to Optimize Simulated Trajectories (POST)," NASA CR-2770, Feb. 1977.

${ }^{9}$ Klumpp, A. R., Atmospheric-Entry, Powered Landing Simulator V4.10C User's Guide, April 23, 2003 (JPL Internal Document).

${ }^{10}$ Knocke, P. C., Wawrzyniak, G. G., Kennedy, B. M., Desai, P. N., Parker, T. J., Golombek, M. P., Duxbury, T. C., and Kass, D. M, "Mars Exploration Rovers Landing Dispersion Analysis," AIAA/AAS Astrodynamics Specialist Conference, AIAA-2004-5093, AIAA, Washington, DC, 2004 (to be published). 